\title{
O ethos do orador na mídia virtual: o razoável e o honesto postos à prova
}

\section{Kathrine Butieri}

\section{Ricardo Ugeda Mesquita}

\footnotetext{
retórica é capaz de resolver uma pendência, por meio da persuasão, nas A sociedades civilizadas, sem necessitar da violência. A confrontação de discursos que precisam ser elaborados com muita engenhosidade e avaliados livremente pelo auditório é um recurso muito eficaz na arte de convencer.

Ao buscar a persuasão, três grandes fatores da argumentação são necessários, de acordo com as lições aristotélicas: o ethos (caráter moral do orador), o pathos (forma pela qual o auditório recebe os argumentos do orador) e, por fim, o logos (a forma pela qual se expressam os argumentos).

Neste texto, vamos nos deter à análise do ethos, sob a perspectiva aristotélica, certos de que o caráter, equivalente à palavra “ético", originária do grego ethos, é um recurso que certamente leva à persuasão.

Na primeira parte, levantaremos alguns aspectos pertinentes à questão teórica do ethos e da ideia de honestidade no contexto retórico. Na segunda parte, analisaremos de forma pontual o ethos na materialidade discursiva da mídia virtual, de modo a diferenciar os elementos principais dos ethé da mídia dita séria e da chamada sensacionalista.
} 


\section{O ethos como recurso do orador}

O ethos corresponde à imagem que se constrói do orador (ou enunciador) no próprio ato de dizer. Equivale ao caráter, à imagem construída de si no ato da enunciação. Importa ao orador assumir o caráter apropriado ao auditório e àquilo que alega, uma vez que assumir o caráter certo em determinado contexto discursivo permite-lhe inspirar a confiança necessária para que o auditório acredite nele e, assim, escute, com atenção redobrada, aquilo que lhe comunica por meio de seu texto, falado ou escrito.

O conceito de ethos, portanto, não diz respeito àquilo que o orador diz de si explicitamente

é esse dizer sem ter dito que possibilita a eficácia do ethos, seu poder de despertar a crença, a adesão: o leitor é levado a identificar-se com a fala do enunciador, a incorporar um certo modo de ver o mundo; é levado a habitar o mesmo "mundo ético"1.

A ideia de ethos surgiu na Grécia com Aristóteles (384-322 a.C.) e, em Roma, com Cícero (106-43 a.C.) e Quintiliano (35-95), com perspectivas diferentes. Para os gregos, a imagem que o orador criava e mostrava no momento da enunciação, a fim de convencer o auditório, não correspondia, necessariamente, à identidade dele; enquanto para os romanos, o ethos estava ligado aos atributos reais do orador, à sua moral, e não incidia na imagem discursiva criada pelo orador.

De acordo com Heine ${ }^{2}$, o pensamento romano baseava-se nas ideias de Quintiliano e Cícero, famosos oradores da época, para os quais a reputação de um homem pesava mais do que suas palavras. No entanto, conforme a autora, é o pensamento grego e não o romano que lançou as bases para a construção teórica da noção de ethos nos estudos linguísticos.

O ethos pode levar o auditório a ouvir o orador, contudo não é suficiente para cativá-lo e persuadi-lo, como bem lembra Matheus ${ }^{3}$. É por isso que Aristóteles aponta para três tipos de provas que representam técnicas capazes de melhor atingir efeito quando utilizadas de forma complementar e interdependente. À credibilidade (ethos) que "obriga" o auditório a ponderar as palavras do orador, segue-se a capacidade, por parte do orador, de gerir

\footnotetext{
Cavalcanti, 2008, p. 173.

Heine, 2011.

Matheus, 2018.
} 
as emoções (pathos) e assim cativar o auditório; a seguir, é necessário que a presença e o interesse do auditório sejam transformados em adesão "lógica" às teses propostas (logos).

Utilizar essas três técnicas no mesmo discurso é alargar o campo da persuasão desde o caráter moral, passando pelo despertar das emoções, até à racionalidade daquilo que se apresenta perante o auditório.

De acordo com Aristóteles,

é o ethos (caráter) que leva à persuasão, quando o discurso é organizado de tal maneira que o orador inspira confiança. Confiamos sem dificuldade e mais prontamente nos homens de bem, em todas as questões, mas confiamos neles, de maneira absoluta, nas questões confusas ou que se prestam a equívocos. No entanto, é preciso que essa confiança seja resultado da força do discurso e não de uma prevenção favorável a respeito do orador ${ }^{4}$.

Diante de tal lição, fica clara a força daquilo que o enunciador explicita na enunciação. É o discurso que tem a força necessária para fazer o auditório apreender um orador constituído pelo discurso e não um ente subjetivo que seria a fonte de onde emanaria o discurso. O ethos é uma imagem do autor, não é o autor real; é um autor discursivo, implícito. Diante disso, o ethos é construído discursivamente e não por meio de uma valoração prévia do caráter do orador.

Para Aristóteles, o ethos é a principal prova retórica, ou seja, o maior recurso de que deve o orador lançar mão ao caminhar pelas veredas da persuasão. Assim, entendido o ethos como um dos mais importantes fatores da argumentação, fonte que inspira confiança no orador, interessa-nos destacar as grandes qualidades procuradas pelo auditório no discurso apresentado. Nesse sentido, o grande filósofo preconiza

três são as causas que tornam persuasivos os oradores, e a sua importância é tal que por elas nos persuadimos, sem necessidade de demonstrações: são elas a prudência (phrónesis), a virtude (areté) e a benevolência (eúnoia).Quando os oradores recorrem à mentira nas coisas que dizem ou sobre aquelas que dão conselhos, fazem-no por todas essas causas ou por algumas delas. Ou é por falta de prudência que emitem opiniões erradas ou então, embora dando uma opinião correta, não dizem o que pensam por malícia; ou sendo prudentes e honestos não são benevolentes; por isso, é

4 Aristóteles, 2015. 
admissível que, embora sabendo eles o que é melhor, não o aconselhem. Para além destas, não há nenhuma outra causa. Forçoso é, pois, que aquele que aparenta possuir todas estas qualidades inspire confiança nos que o ouvem ${ }^{5}$.

O ethos está ligado à própria enunciação ou discurso, e não a um saber extra discursivo sobre o orador ou locutor. Então, para dar a imagem positiva de si mesmo, de acordo com Aristóteles, o orador deve se valer de três qualidades: a prudência, a virtude e a benevolência, porque contra essas três virtudes pouco se pode contra-argumentar.

A prudência (phrónesis) refere-se à capacidade de calcular os meios necessários para atingir um fim. Ela é invocada quando se julga ser característico de um homem dotado de sabedoria, prática e prudência, o poder de deliberar bem sobre o que é bom e conveniente para ele, não sob um aspecto particular, mas sob um prisma que contribua para a vida boa em geral.

A virtude (areté), por sua vez, é uma disposição de caráter. Aristóteles distingue duas formas de virtudes: uma "natural", inata e da qual não se pode ter mérito, porque exclui a capacidade racional do cálculo e da escolha, sendo fruto do bom nascimento e da boa educação; outra, virtude propriamente dita, que se adquire por meio do hábito e do agir bem. Apresenta uma imagem agradável de si, porque apresenta simpatia e conexão com o auditório.

A benevolência (eúnoia), a seu turno, é pouco individualizada por Aristóteles e está vinculada ao desejar o bem ao outro de maneira direta e imediata. Automaticamente, a benevolência aparece quando alguém provoca no outro o espírito da amizade com a relação de causalidade em ser prazeroso e ser útil.

Assim, cabe ao orador valer-se desses recursos para garantir sua eficácia discursiva. Nesse sentido, Fiorin ${ }^{6}$ destaca que o orador que se utiliza mais de phrónesis apresenta-se como ponderado, sensato e constrói suas provas muito mais com os recursos do logos do que do pathos ou do ethos; já, o que se vale mais da areté mostra-se como desbocado, franco, temerário e constrói suas provas muito mais com os recursos do ethos; aquele que, a seu turno, prioriza a eúnoia apresenta-se como solidário, um igual, e erige suas provas muito mais com base no pathos, cheio de benevolência. 


\section{O ethos na mídia virtual}

Como lembra Aristóteles, tendemos mais a acreditar em alguém honesto do que desonesto, em alguém sensato do que sem critérios, em alguém franco, do que alguém que parece mentiroso, escorregadio. Assim, acreditamos mais facilmente nas pessoas que transmitem a imagem de ponderação, de honestidade e de coragem. É, novamente, a ideia do ethos que se impõe no contexto persuasivo.

Ainda assim, estudiosos da retórica na contemporaneidade, como Eggs, ampliam esse entendimento e conectam o ethos e o logos, atribuindo grande força às escolhas linguísticas que apontarão para o caráter do orador, fator que poderá conferir maior ou menor eficácia discursiva. Vejamos sua lição:

o lugar que engendra o ethos é, portanto, o discurso, o logos do orador, e esse lugar se mostra apenas mediante as escolhas feitas por ele. De fato, 'toda forma de se expressar' resulta de uma escolha entre várias possibilidades linguísticas e estilísticas ${ }^{7}$.

Diante de tal realidade, Eggs nos lembra uma passagem de Aristóteles, que afirma que "os meios que nos permitem parecer razoáveis (phrónimos) e honestos (spoudaios) devem ser tirados de nossas distinções que concernem às virtudes ${ }^{8 ”}$. Tal colocação serve como base para uma indagação frente à questão da honestidade e da razoabilidade no discurso sobre a mídia virtual ${ }^{9}$.

Eggs , nesse sentido, complementa tal ideia e esclarece que não é preciso "se dar a aparência" de ser honesto e sincero, mas "apresentar-se" honesto e sincero para que o verdadeiro e o justo se imponham e, para isso, é preciso mostrar-se crível e ser percebido como competente, razoável, equânime, sincero e solidário, e, assim, adquirir uma integridade discursiva e retórica.

Na mídia virtual, é possível analisar a integridade discursiva e retórica que inspira confiança a partir de um ethos institucional, relacionado ao modo de dizer que a instituição deseja construir. Nesse percurso, legitima-se o ethos, conforme a lição de Amossy, “(...) ao mesmo tempo, o ethos está ligado ao

\footnotetext{
$7 \quad$ Eggs, 2008, p. 31.

8 Aristóteles, 2015, 1378a6c.

9 A mídia virtual refere-se ao conjunto de meios de comunicação que necessita de recursos eletrônicos ou eletromecânicos para que o usuário final (audiência ou público) tenha acesso aos conteúdos - de vídeo ou áudio, gravados ou transmitidos em tempo real. Disponível em: https://www.google.com/ search?client=firefox-b-d\&q=o+que+\%C3\%A9+m\%C3\%ADdia+virtual. Acesso em: 30 ago. 2019.
} 
estatuto do locutor e à questão de sua legitimidade, ou melhor, ao processo de sua legitimação pela fala ${ }^{10 "}$.

No caso em tela, em que refletimos sobre a mídia virtual, baseamo-nos em dois sites: o site TV Foco e o site de notícias Uol. Em ambos os sites, identificamos, claramente, jornalistas que assumem a função de orador, e quando isso ocorre

o jornalista vale-se, previamente, de uma imagem positiva de si, de um ethos institucional, sustentado na crença da existência de uma competente responsabilidade profissional e goza de um status, reconhecido socialmente, que lhe assegura o dizer e reveste esse dizer de credibilidade ${ }^{11}$.

Eggs, apoiado nos estudos aristotélicos, afirma que toda a ação se realiza pela phrónesis e pela virtude. Complementa, ainda, que a fórmula phrónesis, areté, eúnoia são o mesmo que epieíkeia (honestidade) e mostram-se pelas escolhas deliberadas feitas pelo orador.

Ambas as características poderiam ser inseridas no campo da areté ao refletirmos sobre as características do ethos e substituídas por "honestidade". Ainda assim, ao tratarmos da mídia virtual, questionamos essa imagem, que deve ser encontrada nas recorrências enunciativas de uma totalidade: a obra de um autor, os discursos de um político etc.

Eggs nos apresenta a fala de Aristóteles em que emprega epieíkeia (honestidade) como sinônimo de ethos:

persuadimos pelo ethos, se o discurso é tal que torna o orador digno de crédito, pois as pessoas honestas (epieíkeia) nos convencem mais e mais rapidamente sobre todas as questões em geral (...). Não é preciso admitir (...) que a epieíkeia do orador não contribui em nada para a persuasão; muito ao contrário, o ethos constitui praticamente a mais importante das provas ${ }^{12}$.

Nesse contexto, é válido destacar que o orador deve encontrar argumentos apropriados à noção comum para que o verdadeiro e o justo se imponham. Por isso, é preciso respeitar os topó $i^{13}$ em que o orador mostre

10 Amossy, 2008, p. 17.

11 Ferreira, 2015, p. 20.

12 Aristóteles apud Eggs, 2008, p. 36.

13 O termo topói significa o lugar comum de onde se originam as provas (FERREIRA, 2015, p.70). 
um ethos apropriado à sua idade e à sua situação social e adapte seu discurso ao costume de seu auditório.

Vale lembrar que na retórica de Aristóteles há dois campos semânticos opostos ligados ao termo ethos que representaremos com o seguinte quadro:

Quadro $1^{14}$

\begin{tabular}{|ll|l|l|}
\hline Ethos & moral & Neutro/objetivo \\
\hline Fundado $\longrightarrow$ & epieíkeia & héxis \\
\hline Engloba $\longrightarrow$ & Atitude e virtude & $\begin{array}{l}\text { hábitos, modos e costumes ou } \\
\text { caráter }\end{array}$ \\
\hline
\end{tabular}

Para Eggs, entretanto, essas duas concepções não se excluem, mas constituem as duas faces necessárias a qualquer atividade argumentativa. $\mathrm{O}$ autor estimula a reflexão dessa temática por meio das seguintes perguntas retóricas:

encontrar-se-iam aqui duas concepções contrárias, ou mesmo contraditórias, da força persuasiva do ethos? Convencemos ao mostrar, no discurso, uma moral elevada ou, de modo contrário, ao usar uma expressão adequada ao caráter e ao tipo social ${ }^{15}$ ?

Nesse sentido, Campos ${ }^{16}$ lembra que a totalidade em que se busca o caráter do enunciador é diferencial, construída para os propósitos da análise. Ao estabelecermos os ethé da chamada mídia digital séria ${ }^{17}$ e da sensacionalista, por exemplo, verificamos que os sites de cada um dos tipos precisam ser vistos como constitutivos de uma totalidade distinta. Por exemplo, poderíamos pensar num site como TV Foco (repleto de chamadas sensacionalistas, notícias de artistas e sub celebridades) e compará-lo a um site de notícias como Uol.

Cada um desses sites representa uma totalidade e apresenta os ethé diferentes, conforme mostraremos a seguir:

14 Eggs, 2008, p. 30 (adaptado pelos autores).

15 Eggs, 2008, p. 30.

16 Campos, 2003.

17 A mídia digital considerada séria, em sentido amplo, é aquela que atua pautada em padrões de sinceridade e honestidade, de acordo com as regras morais impostas por uma sociedade. 


\section{Caso Neymar: Justiça pede acesso as 3 investigações que envolvem o jogador}

A justiça pediu que as Polícias Civil de São Paulo e do Rio de Janeiro encaminhem todas as informações que reuniram nas investigações que envolvem Neymar e Najila Trindade. A medida determina que sejam enviadas à Vara da Região Sul 2 de Violência Doméstica e Familiar contra a Mulher, que fica em São Paulo, as apurações do suposto estupro, da suspeita de furto ao apartamento que a modelo morava e da exposição de fotos íntimas de Najila no Instagram do jogador. Este último corre no Rio de Janeiro.

A solicitação da Justiça foi feita em 12 de julho no despacho que concedeu mais 30 dias de prazo para investigação de estupro que corre na 6 ${ }^{\text {a }}$ Delegacia de Defesa da Mulher. O caso segue em sigilo e os motivos que levaram ao pedido de acesso aos inquéritos policiais não foram revelados. A decisão também teve implicações nos laudos que a Polícia Científica elaborou.

O entendimento dos peritos foi que o resultado deveria ser entregue à Vara da Região Sul 2 de Violência Doméstica e Familiar contra a Mulher, o que foi feito. A medida não atrapalhou o trabalho da 6a Delegacia de Defesa da Mulher porque os investigadores podem acessar o laudo por meio eletrônico logo que eles chegam ao fórum.

Outro procedimento que passará pela Justiça é a inclusão no inquérito das imagens de Neymar no hotel em que Najila se hospedou em Paris entre os dias 15 e 17 de maio. As gravações dele chegando e saindo do Sofitel Arc de Triomphe foram aprendidas pela polícia judiciária de Paris. Acordos internacionais estabelecem que o compartilhamento dos vídeos às autoridades brasileiras só pode ser feito mediante solicitação judicial. Está burocracia pode consumir semanas. 
Não há prazo para o inquérito de estupro ser concluído. Quase todo o trabalho foi feito, não há depoimentos a colher, mas são aguardados laudos e as imagens do hotel de Paris ${ }^{18}$.

Podemos observar nesse texto o ethos do orador apropriado e adaptado em seu discurso ao habitus de seu auditório, uma vez que a notícia foi publicada na página de esportes indicada aos leitores de notícias de esportes, de um site considerado sério.

Essa ideia se confirma quando o orador se vale do poder da instituição (notícias Uol) para informar na voz de outra instituição (Poder Judiciário), ainda mais soberana, seu discurso autorizado, para assim inspirar credibilidade e competência em seu discurso.

$\mathrm{O}$ orador apresenta uma integridade discursiva e retórica quando se mostra no apagamento da enunciação "A justiça pediu..." e utiliza, no decorrer do texto, termos relativos à justiça como uma totalidade incontestável de informação: investigações, medida, enviados à vara, apurações, decisão, laudos, procedimentos, solicitação, despacho, aprendidos, depoimentos etc.

Demonstra, também, o orador, isenção e parece razoável ao tratar dos crimes como "suposto estupro" e "suspeita de furto". Assim, o ethos do orador assegura epieíkeia (honestidade) ao adaptar os habitus éticos do auditório e inspirar um site digno de confiança, sério, com conhecimento dos fatos, linguagem técnica e informações precisas da norma padrão sem duplo sentido para um auditório que busca informações e que tem o costume de consultar a página de esportes.

Dessa forma, o processo argumentativo é dirigido ao auditório que aprova conclusões "verdadeiras" a partir da apresentação de um conjunto sólido de justificações que se baseiam nas teses reivindicadas.

Em contrapartida, o site TV Foco fundamenta-se no juízo de valor de seu auditório e não na evidência de provas de um raciocínio analítico, como visto anteriormente, conforme verificar-se-á a seguir:

\section{Nájila Trindade põe pai de Neymar em caso de estupro e ridiculariza o craque: "O que o papai te orientou?"}

18 Pereira, 27 jul. 2019, on-line. 
Caso de acusação de estupro movido por Nájila Trindade contra Neymar ganha novo capítulo e modelo ridiculariza situação do jogador.

Nájila Trindade, que acusa o jogador Neymar de estupro e que viu o caso dela virar uma novela exposta para todo o Brasil, decidiu literalmente quebrar o silêncio sobre o grave crime contra o jogador e revelar novas informações envolvendo a situação polêmica envolvendo o craque.

Em conversa com o site do canal pago ESPN, Nájila Trindade deixou claro que não vai desistir da forte acusação contra Neymar ridicularizou o jogador e acabou envolvendo até o pai do craque em todo o processo que segue correndo na justiça. "E aí, menino Ney? Bateu ou não bateu? O que o papai te orientou a falar?", começou falando a moça, que segue isolada com familiares na Bahia.

"Sua molecagem está atrapalhando os lucros dele. Você não pode ser punido como qualquer pessoa normal, porque te educar pra virar homem faz mal aos negócios", disparou ainda Nájila Trindade deixando claro seu ódio e revolta contra Neymar.

A moça ainda não parou com suas declarações polêmicas e desafiou Neymar a negar tudo olhando nos olhos dela. Nájila Trindade antecipou que pode até assumir que deu os tapas no jogador, como é possível ver no único vídeo que foi divulgado sobre o caso, mas que o craque vai precisar explicar o porquê ela teria tido tal atitude na ocasião.

Em outro trecho do desabafo de Nájila, ela afirma que Neymar precisa assumir os atos dele para que tenha respeito pelo próprio pai, que vive o chamando de menino por aí. "Assuma sua parcela de responsabilidade dessa tragédia pra que assim você comece a ter o respeito do seu próprio pai", seguiu afirmando a moça de forma bastante polêmica. O staf de Neymar foi procurado para comentar o caso, mas até aqui não se pronunciou, segundo o site da emissora de TV. 
Sobre o caso, para quem não sabe, Nájila veio à público acusar Neymar de estupro e agressões. Tudo teria acontecido em viagem para Paris, paga pelo craque para a Brasileira que foi até a Europa conhecer o rapaz. Lá eles tiveram relações sexuais, mas o craque, segundo o que alega Nájila Trindade, teria se descontrolado e cometido o abuso e as agressões. Após a história estourar no mundo todo, a modelo prometeu ter um vídeo de 7 minutos, que comprovaria tudo que estava dizendo. No entanto, o único vídeo divulgado de pouco mais de um minuto, apenas mostrou a moça batendo no jogador. A modelo, por sua vez, alegou que o tal vídeo acabou sendo roubado.

Vale dizer que recentemente o advogado de Nájila Trindade, Cosme Araújo alegou que vai entrar com o mesmo processo contra Neymar na França. Segundo ele, a ideia é iniciar o processo lá, caso a justiça Brasileira acabe por absolver o jogador em relação às acusações de estupro.

Ainda falando do caso, o ex-marido de Nájila Trindade também acabou se envolvendo no caso recentemente. Ele afirmou em entrevista que não acredita que o estupro tenha ocorrido, e que teria falado com a ex-esposa minutos depois, após o tal acontecimento, e que ela só fazia relatado que o jogador havia sido grosseiro com ela. Após as tais declarações, o advogado da modelo, contestou as alegações do ex-marido ${ }^{19}$.

Na notícia veiculada pelo site TV Foco, o orador, da mesma forma que o anterior, mostra um ethos apropriado e adaptado ao discurso que apresenta ao auditório, com argumentos adequados à noção comum. Observamos que o costume de seu auditório é o de acompanhar o cotidiano de notícias das novelas na TV, assunto recorrente nesse site.

Esse jornalismo, considerado sensacionalista, apresenta duplo sentido nas informações, com manchete gritante, ambígua, temática de crime e apelo sexual, por exemplo, "Nájila Trindade põe pai de Neymar em caso de estupro e ridiculariza o craque: 'O que o papai te orientou?"

19 Tura, 28 jul. 2019. 
No decorrer do texto verificamos informações tendenciosas e irrelevância na informação, com o intuito de causar outros efeitos de sentido no interlocutor. Os termos como "ganha novo capítulo" e "viu o caso dela virar uma novela" fazem parte de um discurso adaptado ao habitus de seu auditório.

Como em um romance "realista", as informações são narradas com personagens complexos, problemáticos e envolvidos em suas paixões, para construir uma situação polêmica. O orador mostra uma maneira de viver e de mostrar em seus "personagens" ethé diferentes.

Observamos, também, o uso de duplo sentido, exageros e adjetivações que nos levam a considerar o site sensacionalista. Vejamos algumas ocorrências nesse sentido:

- Duplo sentido: Nájila Trindade põe pai de Neymar em caso de estupro; o que o papai te orientou?

- Exagero: grave crime, forte acusação, desabafo, segue isolada, desafiou Neymar, deixa claro seu ódio.

- Adjetivação: ridiculariza, "menino", molecagem.

A interpretação tendenciosa da entrevista feita a Nájila apresenta um argumento que não é lógico, visto que Nájila se vale do pathos para cativar seu auditório: "assuma sua parcela de responsabilidade dessa tragédia pra que assim você comece a ter o respeito do seu próprio pai”. É assim que Nájila encontrou, dentro do discurso dominante, virtuosidade para a construção de seu ethos.

A seu turno, o site TV Foco repetiu a mesma ideia com outras palavras e valeu-se da figura de presença para persuadir: "ela afirma que Neymar precisa assumir os atos dele para que tenha respeito pelo próprio pai, que vive o chamando de menino por aî". É clara a artimanha da repetição persuasiva para criar uma presença na consciência do auditório.

Essas marcas composicionais permitem compor o ethos da mídia digital séria e da sensacionalista.

O sujeito do estilo, como ethos ou imagem de um orador colhida pelo auditório a partir daquilo que é dito, interpreta as coisas do mundo. Dessa interpretação decorre um princípio de julgamento ético (radicado no interior de um percurso gerativo do sentido). O mesmo sujeito experimenta emoções diante do mundo per- 
cebido, e, nesse âmbito da experiência sensível do pensamento, desvelam-se os vividos ${ }^{20}$.

Os ethé das mídias digitais podem ser construídos pelo interlocutor e interpretados pelo auditório. De um lado, o tom sério, brando, a voz que não se eleva; do outro, o tom jocoso, rude, franco, que se exibe sem "frescuras", sem contenção. É um corpo (totalidade) avesso ao freio, de gestos abruptos. Ele não fala, grita.

Nesse momento, não importam os vários fazeres dos sujeitos reais, mas a apreensão da imagem do enunciador veiculada pelo texto. É como se esse sujeito, esse ethos, fosse o eu-lírico de uma poesia. É um todo, uma imagem produzida pelo discurso, que transmite por meio dos variados elementos composicionais capazes ou não de gerar adesão e a esperada eficácia do ato retórico.

\section{Considerações finais}

O orador constrói seu ethos no momento do ato retórico e isso pudemos observar nos exemplos apresentados. Sabemos que a areté (benevolência, adaptação perfeita, excelência, virtude) é uma palavra grega que expressa o conceito de excelência, ligado à noção do cumprimento do propósito ou da função a que o indivíduo se destina e tal cumprimento foi amplamente apresentado pela análise dos textos selecionados da mídia digital.

Nesse contexto comunicativo, o jornalista almeja atingir seu público e comunicar sua ideia com eficácia, apoiado na fórmula phrónesis, areté, eúnoia que é sinônimo de epieíkeia (honestidade). Tal perspectiva é mostrada pelas escolhas deliberadas feitas pelo orador.

Para tanto, a honestidade do jornalista, aqui orador, é colocada à prova em textos como o extremamente sensacionalista por nós apresentado; entretanto, é possível afirmar que o enunciador está sendo fiel àquilo que quer comunicar, não à realidade, que, também, é relativa e sempre questionável.

Entendemos que a Nova Retórica, especialmente a partir da análise do segundo texto, não considera o apelo sensacionalista como defeito de linguagem, mas assume e compreende essa inexatidão na argumentação em

20 Discini, 2016, p. 25. 
contextos cotidianos informais preocupada com o auditório e com a forma pela qual o orador coordena seus pensamentos e suas ações.

Nesse diapasão, uma análise retórica dos excertos objeto deste texto permite-nos afirmar que, habilmente, em ambos os contextos, os jornalistas, aqui oradores, consideraram as possibilidades de interação do auditório, desde a escolha da temática até à abordagem lexical e à forma de construção das ideias expostas e caminham por uma trilha comprometida com aquilo que querem veicular. Há uma linha tênue entre o que é e o que fazem parecer ser. Ainda assim, a efetividade retórica se concretiza, para diferentes auditórios, por meio de diferentes oradores, com diferentes ethé.

A lição aristotélica relaciona o parecer razoável e honesto ao campo das virtudes. A honestidade e o razoável aqui são questionados, mas, sobretudo, sob a égide da Nova Retórica, inter-relacionados no ato enunciativo jornalístico das mídias digitais, o momento maior de construção do ethos do orador.

Assim, o orador ou enunciador, nesse contexto, é o jornalista: não, necessariamente, o jornalista "de carne e osso", mas a imagem que exara do ethos que construiu por meio de sua obra. 


\section{Referências}

AMOSSY, R. (Org.). Imagens de si no discurso: a construção do ethos. São Paulo: Contexto, 2008.

ARISTÓTELES. Retórica. Tradução do original em grego de Manuel Alexandre Júnior, Paulo Farmhouse Alberto e Abel do Nascimento Pena. São Paulo: Folha de S. Paulo, 2015. (Coleção Folha. Grandes nomes do pensamento, 1)

CAMPOS, N. D. de. O estilo nos textos. São Paulo: Contexto, 2006.

CAVALCANTI, J. R. Considerações sobre o ethos do sujeito jornalista. In MOTTA, A. R.; SALGADO, L. (Org). Ethos discursivo. São Paulo: Contexto, 2008.

DISCINI, N. Éthos e estilo. In: LIMA, E. S. de; GEBARA, A. E. L.; GUIMARÃES, T. F. (orgs.) Estilo, éthos e enunciação. Franca: Unifran, 2016.

EGGS, E. Ethos aristotélico, convicção e pragmática moderna. In AMOSSY, R. (Org) Imagens de si no discurso: a construção do ethos. São Paulo: Contexto, 2008, p. 29-44.

FERREIRA, L. A. Leitura e persuasão - princípios de análise retórica. São Paulo: Contexto, 2015

FIORIN, J. L. Argumentação. São Paulo: Contexto, 2016.

HEINE, P. V. B. A construção do ethos da garota adolescente na revista Capricho. In: HEINE, P. HEINE, L. (orgs). Entre o texto e o discurso. Simões Filho: Kalango, 2011:141-164.

MATEUS, S. Introdução à retórica no século XXI. Covilhã: Editora LabCom. IFP, 2018. 
